\title{
A TUTELA MULTINÍVEL DE DIREITOS NO ÂMBITO BRASILEIRO
}

\author{
Jadson Oliveira ${ }^{1^{*}}$ \\ Joel Meireles Duarte ${ }^{2 * *}$ \\ Caroline dos Santos Chagas ${ }^{3 * * *}$
}

\section{Resumo}

Este artigo visa explorar a Tutela Multinível de Direitos Humanos para, introduzindo seu conceito, demonstrando sua origem e aplicabilidade no âmbito internacional, determinar as nuances da proteção multinível de Direitos Humanos no sistema brasileiro. Serão abordadas lições gerais sobre a tutela multinível, analisando-a em nível global e nos sistemas europeu, americano e latino-americano, e suas nuances no Brasil, ainda, discorrendo sobre as vantagens e desvantagens do sistema multinível, concluindo-se pela inexistência de um sistema multinível estruturado de Direitos Humanos no âmbito brasileiro, recorrendo às publicações em periódicos, artigos científicos, dissertações e teses sobre o tema com pesquisa bibliográfica e documental.

Palavras-chave: Tutela Multinível; Constitucionalismo Multinível; Sistema Multinível Direitos Humanos; Proteção.

\section{THE MULTI-LEVEL PROTECTION OF RIGHTS IN THE BRAZILIAN SCOPE}

\begin{abstract}
This article aims to explore the Multilevel Protection of Human Rights to, introducing its concept, demonstrating its origin and applicability in the international sphere, to determine the nuances of the multilevel protection of Human Rights in the Brazilian system. General lessons about multilevel protection will be addressed, analyzing at the global level and in the European, American and Latin American systems, and its nuances in Brazil, also discussing the advantages and disadvantages of the multilevel system, concluding by the inexistence of a structured multilevel system of Human Rights in the Brazilian scope, using publications in periodicals, scientific articles, dissertations and theses on the subject with bibliographical and documentary research.
\end{abstract}

Keywords: Multilevel Tutelage; Multilevel Constitutionalism; Multilevel System; Human Rights; Protection.

1 Pós-Doutor em Democracia e Direitos Humanos, pelo Ius Gentium Conimbrigae - IGC/CDH, da Faculdade de Direito da Universidade de Coimbra. Professor do curso de graduação e mestrado. Advogado. jadson.oliveira@pro.ucsal.br. http://orcid.org/0000-0003-1599-6552

2 Mestrado em Planejamento Territorial e Desenvolvimento Social pela Universidade Católica do Salvador (2017). Advogado e Coordenador Jurídico da Primeira Secretaria da Assembleia Legislativa do Estado da Bahia (ALBA). joelmeireles@live.com. http://orcid.org/0000-0001-5403-1345

3 Advogada, pós-graduada em Direito Civil, Comercial e do Consumidor pela Associação Unyhana. Mestranda em Direitos Fundamentais e Alteridade pela Universidade Católica de Salvador. carolinechagas.adv@ gmail.com. http://orcid.org/0000-0002-9328-8423 


\section{INTRODUÇÃO}

A análise da Tutela Multinível enquanto meio jurisdicional de proteção dos Direitos Humanos é o objeto do presente trabalho, que aborda a temática trazendo o escopo de responder ao seguinte questionamento: existe, no âmbito brasileiro, um sistema multinível estruturado de proteção dos Direitos Humanos?

Aborda-se a temática em razão da problemática que envolve a questão da Tutela Multinível de Direitos em âmbito global e, especialmente, em âmbito nacional, dada a falta de uma organização estrutural que garanta a atuação e coercitividade de uma jurisdição internacional no cenário interno Brasileiro.

O tema a ser desenvolvido ao longo do trabalho possui inequívoca relevância, aferível no efetivo interesse que desperta no campo doutrinário e jurisprudencial e por afetar diretamente o interesse da pessoa humana e o cenário internacional de proteção dos Direitos Humanos, que tem tomado proporções cada vez maiores por Ordens Jurídicas extremamente interligadas.

Para atingir o fim acima delineado, incursiona-se, no primeiro capítulo, pela contextualização histórica da Tutela Multinível e sua conceitualização, de maneira a permitir o entendimento geral do tema a ser desenvolvido.

Nesta linha de raciocínio, apresenta-se no segundo capítulo a contextualização geográfica da proteção multinível de Direitos Humanos, com o fito de demonstrar a existência e estrutura do sistema multinível no âmbito europeu, global, interamericano e latinoamericano.

Introduzindo, sucintamente, uma explicação acerca da posição das fontes internacionais do Direito no ordenamento jurídico pátrio, reservou-se, no terceiro capítulo, ao tema central do presente trabalho, para determinar se há, no âmbito brasileiro, um sistema multinível de proteção dos direitos humanos, ao tempo em que, apresentou-se a comparação dos níveis de jurisdição internos para demonstrar se há proteção multinível em âmbito subnacional.

No quarto capítulo, faz-se um pequeno adendo acerca das vantagens e desafios da Tutela Multinível de Direitos humanos, buscando, ao apresentá-las, conduzir a lume conclusões do próprio leitor acerca do tema.

Finalmente, apresenta-se a conclusão do autor acerca do problema trabalhado. 
No que concerne à metodologia, a presente pesquisa parte do pressuposto que a unicidade metodológica não é apta a alcançar o desenvolvimento científico vivenciado atualmente.

No tocante a metodologia desta pesquisa, utilizar-se-á, o método cartesiano defendido por René Descartes (2007), partindo das ideias mais gerais para, gradativamente, efetuar uma análise dos objetos mais específicos.

Bem como, propõe-se ainda a utilização do método lógico-dedutivo desenvolvido por Popper (2004). De acordo com o autor, todo conhecimento inicia com um problema, o que acontece também na pesquisa científica e, bem assim, partiremos das teses popperianas no desenvolvimento dos conceitos relativos à verdade e à explicação, que tornam possível a análise do conceito da "aproximação da verdade" e do "poder explicativo" ou "conteúdo explicativo" de uma teoria.

Tais conceitos são compreendidos pelo autor como dois dos mais importantes para a lógica do conhecimento ou metodologia. Isso porque, da análise de enunciados, em que pese estes sejam apenas verdadeiros ou falsos, um pode representar uma "melhor aproximação da verdade" do que outro, se seu "poder explicativo" for maior que o do outro.

No sentido de analisar essa "melhor aproximação da verdade", repousaremos nos focos normais da investigação científica estabelecidos por Kuhn (1988, p. 46): a classe de fatos que o paradigma mostrou ser reveladora da natureza das coisas; os fenômenos que podem ser diretamente comparados com as predições da teoria do paradigma; e o trabalho empírico para articular a teoria do paradigma através da resolução dos seus problemas e ambiguidades residuais.

Em tempo, far-se-á a utilização como método de abordagem qualitativa, segundo o qual, o pesquisador procura-se entender acerca do fenômeno que é observado. Segundo Coimbra, no momento da perquisição do objeto deve ser levado em consideração a influência da cultura no comportamento humano e social, de modo que, deverá ser o pilar de explicação desse objeto.

Em breves linhas, sob a ótica do método qualitativo, o pesquisador analisa os dados inseridos num cenário natural, a fim de interpretar o seu significado, explorando suas ideias e preocupações sobre o tema, e por fim, alcançando uma conclusão.

Destarte, para a materialização da presente pesquisa, buscou-se a utilização de fontes de pesquisa bibliográficas e documentais, decorrente do cunho hegemonicamente doutrinário das premissas acerca do panorama de estudo proposto, recorrendo-se às doutrinas nacionais e 
estrangeiras para tratar dos aspectos constitucionais e de direitos fundamentais atrelados à tutela multinível.

\section{A TUTELA MULTINÍVEL DE DIREITOS HUMANOS}

Régis Willyan da Silva Andrade (2017, p. 76) inicia seus ensinamentos acerca do sistema multinível de direitos tecendo comentários acerca da distinção entre Direitos Humanos e Direitos Fundamentais para, então, esclarecer que o constitucionalismo moderno busca novas concepções de "Estado, soberania e governabilidade", através do qual se criam organizações e ferramentas de efetivação e proteção desses Direitos através de um modelo multinível.

O sistema multinível teve sua primeira expressão na Europa, com advento da União Europeia, que, no final da década de oitenta, com a integração dos Estados-membros, refletiu uma ruptura de paradigmas, de sorte que se desenvolveram instituições externas aos tradicionais Estado-nação que, em que pese continuassem como "[...] atores de governabilidade desse novo sistema [...]", acabam por romper a noção de soberania "[...] intocável e estatizada [...]", e diversos atores passam a integrar ao sistema nos âmbitos nacional, subnacional e supranacional (ANDRADE, 2017, p. 83).

Nesse sentido, Alice Rocha da Silva e Matheus Passos Silva (2016, p. 25) explicam que as alterações político-jurídicas acontecidas no século XX no continente europeu fizeram surgir organismos internacionais que trouxeram consigo a criação da então chamada tutela multinível de direitos.

É de fato muito lógica a compreensão do termo “multinível”, posto que neste cenário criou-se um espaço no qual o mesmo assunto se sujeitou, concomitantemente, à regulação de instituições subnacionais, nacionais e supranacionais, extrapolando o tradicional "Estadonação".

O sistema multinível surgiu no cenário europeu com o fito de dar coesão às diferentes regiões do continente e possibilitar um diálogo entre as províncias e as instituições supranacionais, para viabilizar a “[...] interlocução entre os Direitos Fundamentais de âmbito doméstico, com os Direitos Humanos de âmbito supranacional.” (ANDRADE, 2017, p. 84).

Com efeito, como bem assevera René Urueña (2014, p. 17), a política multinível impactou profundamente a política de coesão europeia porquanto legitimava entidades subnacionais dos Estados-membros para dialogar diretamente com instituições 
supranacionais, sem que fosse necessária a figura do governo nacional para intermediar a relação.

Enquanto por um lado essa quebra de paradigma possibilita "[...] uma maior e mais completa proteção ao oferecer diferentes níveis[...]”, de outro lado, estabelecendo “[...] uma nova ordem jurídica comunitária, com supremacia nos sistemas jurídicos nacionais dos Estados-membros, passa-se a descrever uma nova modalidade de constitucionalismo denominada de multinível." (URUEÑA, 2014, p. 17).

Essa compreensão pressupõe que a tutela dos direitos fundamentais não se limita mais somente aos próprios Estados-nação, superando a noção de "soberania-território-povo", passando a ser competência também de outras instituições (DA SILVA; SILVA, 2016, p.45).

Isso porque, a proteção e efetivação dos direitos humanos não pode ficar adstrita apenas ao Estado, mormente em razão de ter se comprovado historicamente que o próprio Estado é capaz de infringir os direitos fundamentais que ele mesmo institui e garante, como ocorreu no Holocausto (DA SILVA; SILVA, 2016, p. 47).

De forma que se faz necessária uma coordenação entre Estados e instituições diversos, para prover maior proteção à pessoa humana e à sua dignidade, o que aconteceu no cenário europeu pós Segunda Guerra Mundial, com o advento do constitucionalismo multinível (DA SILVA; SILVA, 2016, p. 47).

Acerca deste, ensinam os autores que se fundamenta em quatro elementos básicos: o necessário caráter pós-nacional das constituições atuais; a posição central do cidadão; a interdependência entre as diferentes esferas de constitucionalidade e a multiplicidade de identidades do cidadão europeu. Mas, não apenas isso, destaca-se também a necessária ausência de hierarquia no relacionamento entre os Estados-membros e a União Europeia.

Destoando em partes dos autores até então apresentados, em sua tese de doutorado, Carmen Montesinos Padilla (2015, p. 16) afirma que a delimitação conceitual de Tutela Multinível exige uma aproximação à teoria do constitucionalismo multinível, todavia, em sua concepção, não há uma relação de dependência recíproca entre estes paradigmas, posto que tutela multinível precede no tempo o constitucionalismo multinível e sua sobrevivência.

Para a autora (PADILLA, 2015, p. 17), o constitucionalismo multinível foi desenvolvido para conceituar a estrutura constitucional específica do sistema comunitário europeu, porquanto sua concepção eleva os tratados constitutivos das comunidades europeias à categoria de constituição e se concentra na conexão entre os ordenamentos nacionais e o comunitário europeu. 
Ainda assim, porém, Padilla (2015, p. 18) defende que a tutela multinível de direitos pode existir sem que a União Europeia tenha adotado uma verdadeira constituição.

Em suas teses, a autora apresenta a tutela multinível como "[...] complexa estrutura de mecanismos de proteção de direitos e liberdades e as relações existentes entre os organismos nacionais, internacionais e/ou supranacionais que se encarregam de sua fiscalização[...]" (PADILLA, 2015, p.19) e, por isso, Padilla (2015, p.19) diz que os estudiosos do assunto entendem a plena judicialização do sistema europeu como verdadeiro fundamento jurídico da proteção multinível dos direitos.

Apesar disso, Padilla (2015, p. 19), por entender a tutela multinível como “[...] a existência de uma pluralidade de mecanismos de garantias resultantes das limitações do Estado soberano para fazer frente aos desafios que levantam a efetiva proteção dos direitos[...]", acredita que pode se situar a origem dessa doutrina na criação da Organização das Nações Unidas (PADILLA, 2015, p. 19).

Em outras palavras, a autora esclarece que a tutela multinível existe a partir do momento que existem distintas esferas de proteção dos direitos além das fronteiras do Estado, todavia, a existência não se confunde com a eficácia e medidas de garantias presentes em cada nível de proteção dos direitos (PADILLA, 2015, p. 19).

O que ocorre, porém, é que no cenário europeu os direitos e liberdades se infiltraram no direito originário de sorte que, na atualidade, a União Europeia dispõe de um catálogo próprio de direitos ao qual se atribui o mesmo valor jurídico dos tratados constitutivos e, portanto, em nível supranacional, também existe um órgão jurisdicional com competência material de direitos que se relacionam com os juízes e tribunais nacionais em grau de cooperação (PADILLA, 2015, p. 22).

\section{A TUTELA MULTINÍVEL DE DIREITOS HUMANOS NO SISTEMA EUROPEU, EM NÍVEL GLOBAL, INTERAMERICANO E LATINO-AMERICANO}

\subsection{OS NÍVEIS DE PROTEÇÃO DOS DIREITOS HUMANOS NO MODELO EUROPEU}

O sistema europeu de proteção de direitos humanos possui vocação eminentemente jurisdicional, cujo órgão decisório é um Tribunal que se caracteriza por ser independente e imparcial, cujo procedimento é de caráter contraditório e decisões de caráter vinculante, que valoriza sempre o caráter jurisdicional da proteção (URUEÑA, 2014, p. 181). 
Em suas lições, Urueña (2014, p. 17) explica que, no modelo Europeu, os direitos humanos são tutelados em, pelo menos, quatro níveis: subnacional, nacional, supranacional e internacional.

Em âmbito subnacional, o autor esclarece que as unidades podem vir a consagrar em suas ordens jurídicas certos direitos humanos e, nessa ocasião, é possível verificar direitos reconhecidos na esfera sub-estatal em relação hierárquica com a ordem constitucional nacional, de forma que "[...] o debate sobre a proteção multinível dos direitos humanos neste caso é confundido com o estudo do direito constitucional nacional do respectivo Estado.” (URUEÑA, 2014, p. 17).

Neste âmbito, faz-se mister a equiparação ao ordenamento jurídico brasileiro, haja vista que os Estados Federados também possuem suas próprias constituições e se submetem à Carta Magna, podendo-se até mesmo falar em proteção multinível interna, interjurisdicional, adendo que será sucintamente apresentado no próximo capítulo.

Em âmbito nacional, por sua vez, “[...] as constituições nacionais de cada Estadomembro incluem nos seus artigos direitos que o respectivo Estado-nação queira reconhecer aos seus cidadãos e residentes.” (URUEÑA, 2014, p. 18).

Já em âmbito supranacional, “[...] os direitos humanos também são protegidos pelo direito de União" (URUEÑA, 2014, p. 18), pela presença do Tribunal de Justiça da União Europeia e pela Carta dos Direitos Fundamentais, enquanto os instrumentos se dedicam a proteger violações por parte da União Europeia e seus órgãos, "bem como os Estadosmembros, quando os mesmos apliquem o direito da União.” (URUEÑA, 2014, p. 18).

Por fim, em âmbito internacional há a proteção dos direitos pelo Sistema Europeu de Direitos Humanos, cujo tribunal competente é o Tribunal Europeu de Direitos Humanos, que é um tribunal internacional com funções similares (na Europa) às realizadas pelo Tribunal Interamericano de Direitos Humanos (URUEÑA, 2014, p. 18).

\subsection{A PROTEÇÃO GLOBAL DE DIREITOS HUMANOS}

A nível global, a proteção de direitos humanos ficou a cargo da Organização das Nações Unidas, da qual 193 países são signatários.

A Carta das Nações Unidas (ONU, 1945), de 1945, proclamou a dignidade da pessoa humana e o respeito aos direitos humanos como seu propósito, tendo a Declaração Universal dos Direitos Humanos (DUDH) posicionado os Direitos Humanos em igualdade ao princípio 
da soberania dos Estados, o que transformou o cenário do direito internacional, ao passo em que erodiu e relativizou a soberania Estatal em favor de obrigações internacionais a serem assumidas pela sociedade como um todo, na proteção de Direitos Humanos (BREGAGLIO, 2014, p. 101).

Todavia, como explica Renata Bregaglio (2014, p. 101)., em que pese a Declaração Universal de Direitos Humanos “[...] enumere e defina os mais importantes direitos políticos, econômicos, sociais e culturais civis, não determina qualquer direito de reclamação dos particulares perante instâncias internacionais, nem estabelece qualquer outro mecanismo jurídico de controle."

Sendo assim, é fácil perceber que a ONU não representa, por si só, uma instituição supranacional/internacional/global ativa da tutela multinível de Direitos Humanos, fazendo-se necessário que seus órgãos promovam essa proteção, especialmente a Assembleia Geral, Conselho de Segurança, Conselho de Tutela e a Corte Internacional de Justiça.

\subsection{A PROTEÇÃO INTERAMERICANA DE DIREITOS HUMANOS}

Felipe Arias Ospina e Juliana Galindo Villarreal (2014, p. 145) destacam que o Sistema Interamericano de Direitos Humanos hoje representa papel importante na proteção e promoção dos Direitos Humanos nas Américas, o que foi possível por meio da "consolidação de um quadro normativo vinculativo para os Estados em matéria de Direitos Humanos, e a consequente criação dos organismos responsáveis por garantir a segurança dos mesmos", bem como, através de "[...] procedimentos específicos que monitorem e avaliem o cumprimento das obrigações adquiridas pelos Estados-membros.” (OSPINA; VILLARREAL, 2014, p. 145).

O Sistema entrou em vigor em 1948, com a adoção da Carta da Organização dos Estados Americanos, o Tratado Americano de Soluções Pacíficas e a Declaração Americana dos Direitos e Deveres do Homem.

Dos aludidos instrumentos, os autores afirmam que, juntamente a Carta da OEA (1969), a Declaração Americana dos Direitos e Deveres do Homem foi o instrumento de maior relevância de proteção internacional dos Direitos Humanos por parte dos Estadosmembros. Todavia, a aludida declaração não foi recebida como convenção de efeitos vinculativos para os Estados (OSPINA; VILLARREAL, 2014, p. 146). 
Apesar disso, a Corte Interamericana de Direitos Humanas, em sua Opinião Consultiva n. 10/90, declarou que aos Estados-membros da OEA, a Declaração constitui fontes de obrigações internacionais com efeitos jurídicos.

Ainda assim, fez-se necessário o desenvolvimento, em 1969, do Pacto de San José da Costa Rica, instrumento com força vinculativa que faz cumprir as obrigações em matéria de direitos humanos nas Américas (OSPINA; VILLARREAL, 2014, p. 147).

\subsection{A PROTEÇÃO LATINO-AMERICANA DE DIREITOS HUMANOS}

Assim como explicado no capítulo anterior, é sabido que o sistema multinível europeu é o mais antigo e sedimentado, que vem seguido do interamericano, o que leva ao estudo da possibilidade de um sistema multinível de proteção dos Direitos Humanos e Fundamentais na América Latina.

Obviamente, existe a proteção dos direitos humanos em âmbito nacional e subnacional, através das constituições nacionais dos países americanos, assim como, pelo pacto de San José da Costa Rica e pelo Sistema Interamericano de Direitos Humanos.

Todavia, como explica Urureña (2014, p. 19), “[...] não existe proteção no âmbito supranacional, como demonstram as experiências do Mercosul e da Comunidade Andina.”

Em que pese existam instrumentos e documentos de cooperação internacional que se debrucem sobre os direitos humanos na comunidade interamericana, a exemplo da Carta de Direitos Humanos, Declaração de Las Leñas, Reunião das Altas Autoridades na área de Direitos Humanos, são todos instrumentos intergovernamentais que "[...] não estabelecem um verdadeiro regime comunitário de direitos humanos dentro do Mercosul, com efeito e supremacia sobre a ordem jurídica nacional.” (URUEÑA, 2014, p. 20).

Assim, atesta-se que não há, de fato, um âmbito supranacional de proteção dos direitos humanos na América Latina, o que, para alguns doutrinadores e comentaristas, é reflexo de um problema de "progresso e desenvolvimento", porquanto na América Latina tem-se um processo de desenvolvimento ainda muito “jovem” (URUEÑA, 2014, p. 20).

O que se vislumbra, portanto, é que no âmbito latino-americano, a tutela multinível “[...] corresponde a nada mais (e nada menos) que as ferramentas, possibilidades e riscos oferecidos pela interação entre os sistemas jurídicos nacionais e o Sistema Interamericano de Direitos Humanos.” (URUEÑA, 2014, p. 22). 
Enquanto que, para se promover a interação entre a proteção internacional e nacional, como propõe Urureña $(2014$, p. 23), podem ser pensadas formas: de uma perspectiva nacional, através da qual a interação pode ser observada a partir do direito interno dos países da região; e de uma perspectiva global, pela qual se observa de forma externa aos direitos dos Estados, que pode ser denominado "Comunidade Internacional".

\section{A TUTELA MULTINÍVEL DE DIREITOS HUMANOS NO ÂMBITO BRASILEIRO}

\subsection{A POSIÇÃO DOS TRATADOS INTERNACIONAIS DE DIREITOS HUMANOS NA LEGISLAÇÃO NACIONAL}

O Direito brasileiro reconhece a existência de tratados e costumes internacionais e é farta a jurisprudência nacional acerca da aplicação e interpretação dessa fonte nas decisões judiciais (GALINDO; MAUÉS, 2014, p. 289).

Os tratados de direitos humanos adotam normalmente o mesmo procedimento de incorporação ao direito brasileiro que os demais tratados internacionais, diferenciando-se somente quando a intenção é que seja equivalente à Emenda Constitucional. Todavia, não há obrigatoriedade alguma para que os tratados de direitos humanos passem por esse procedimento específico (GALINDO; MAUÉS, 2014, p. 291).

Como ensinam George Galindo e Antônio Maués (2014, p. 291), o Supremo Tribunal Federal já teve diferentes entendimentos acerca da posição dessas fontes no ordenamento jurídico interno, tendo sido considerados como de nível supra-constitucional, constitucional e legal, sendo essa última a posição que o STF adotou por vários anos em homenagem ao regime constitucional anterior a 1988.

Todavia, atualmente, após a Emenda Constitucional n. 45, promulgou-se que os tratados internacionais de direitos humanos seriam incorporados ao ordenamento jurídico brasileiro como emendas constitucionais, assim como, constitucionalizou a adesão do Brasil ao Tribunal Penal Internacional, demonstrando a valorização do direito internacional dos Direitos Humanos (GALINDO; MAUÉS, 2014, p. 299).

Tal fato se deu justamente em razão da tendência do constitucionalismo multinível e a necessidade de se prestigiar as normas internacionais de direitos humanos, bem como, pela evolução do sistema interamericano de proteção dos direitos humanos e as obrigações advindas dos princípios de direitos internacionais, às quais a mera supralegalidade dessas 
fontes não era mais suficiente à promoção e efetividade dos Direitos Humanos (GALINDO; MAUÉS, 2014, p. 301).

Há de se destacar, contudo, que assim como as Emendas Constitucionais, os tratados internacionais de direitos humanos constitucionalizados são passíveis de controle de constitucionalidade caso violem cláusulas pétreas. Assim, não é impossível que um tratado constitucionalizado possa vir a ser considerado inconstitucional (GALINDO; MAUÉS, 2014, p. 302).

A exemplo disso, Galindo e Maués (2014, p. 304) relembram que "[...] a recente divergência entre o STF e a Corte Interamericana de Direitos Humanos sobre a adequação da lei brasileira e à Convenção Americana pode levar tribunais brasileiros a priorizar a Constituição Nacional." Tal situação, por sua vez, seria capaz de tornar inconstitucional o tratado internacional.

\subsection{A EXISTÊNCIA DE TUTELA MULTINÍVEL DE DIREITOS HUMANOS NO ÂMBITO BRASILEIRO}

Clarissa de Oliveira Gomes Marques da Cunha (2020, p. 498-529), assevera que o constitucionalismo multinível “[...] sugere uma reestruturação dos Estados por meio do surgimento de uma forma de governança compartilhada.

Flávia Danielle Santiago Lima e Drailton Ferreira Vieira (2018, p. 56), por sua vez, destacam que essa “[...] convergência de ordens jurídicas nacionais e supranacionais[...]" é fruto do "[...] reconhecimento da necessidade de garantias que ultrapassem a relação cidadão vs Estado Nacional, mas que integrassem os seres humanos para além das organizações políticas." (LIMA; VIEIRA, 2018, p. 56).

Citando Flávia Piovesan, os autores (LIMA; VIEIRA, 2018, p. 56) explicam que é possível classificar os direitos fundamentais em três grupos: expressos na constituição; implícitos, decorrentes do regime dos princípios adotados pela Carta constitucional; e decorrentes dos tratados internacionais subscritos pelo Brasil.

Num sistema multinível, esses direitos são garantidos por esferas nacional, supranacional e internacional. E, no caso brasileiro, por expressa vinculação e previsão constitucional, tem-se o reconhecimento dos níveis nacional, regional e global. 
Assim, para Lima e Vieira (2018, p. 57), uma vez "[...] reconhecida a imperatividade dos tratados internacionais de direitos humanos, pode-se falar em uma proteção multinível destes[...]" nas esferas garantidoras nacional, supranacional e internacional.

Ocorre, porém, que a proteção multinível efetiva dependeria não apenas de suas disposições materiais, mas também de mecanismos de implementação. Todavia, como bem destacam os autores, essas múltiplas proteções dependem do diálogo entre os diversos níveis (LIMA; VIEIRA, 2018, p. 57).

Atualmente, não existe de fato um sistema multinível estruturado, a nível supranacional, do qual o Brasil seja integrante. Apesar disso, tais direitos encontram-se protegidos pela Constituição Nacional dos países latino-americanos, pelo Pacto de San José da Costa Rica (OEA, 1969) e pelo Sistema Interamericano.

A respeito disso, embora existam projetos de lei e emenda constitucional que versem sobre a execução de sentenças da Corte Interamericana pelos Tribunais Nacionais, atualmente não existe qualquer norma interna que discipline o assunto, o que "enfraquece a autoridade das decisões internacionais e a previsibilidade quanto ao seu cumprimento no direito interno.” (GALINDO; MAUÉS, 2014, p. 307).

Há de se destacar, contudo, que, enquanto Estado-membro da OEA, o Brasil se torna participante dos tratados do Sistema Interamericano que criam os Tribunais Internacionais e internaliza suas normas, diferentemente dos tribunais estrangeiros. Sendo assim, as sentenças dos Tribunais Internacionais não carecem de qualquer homologação e integram o ordenamento jurídico interno (GALINDO; MAUÉS, 2014, p. 308).

Ocorre, porém, que a ausência normativa acerca das execuções das sentenças internacionais proferidas pela Corte Interamericana dificulta a sua efetividade, especialmente pela própria ausência de orientação da própria Corte sobre meios específicos para o cumprimento de suas decisões.

Tal lacuna, por si só, é suficiente a demonstrar a necessidade de um diálogo maior entre os atores da tutela multinível no âmbito interamericano e, especialmente, no âmbito brasileiro.

É o que se observa também no cerne da jurisdição do Tribunal Penal Internacional, à qual o Brasil se submete em razão da adesão ao Estatuto de Roma, pelo próprio decreto n. 4388 de 2002 (BRASIL, 2002), que promulga a adesão brasileira, declara-se, de logo, que é dever de cada Estado-parte realizar sua jurisdição penal frente a um crime internacional e, 
bem assim, o Tribunal Penal Internacional teria função complementar aos tribunais nacionais e, por assim dizer, subsidiária.

O que se conclui, portanto, é que o Tribunal Penal Internacional não realiza uma proteção em nível, posto que não age em grau de igualdade hierárquica ou por cooperação, mas sim em nível subsidiário, quando o Estado-nação aderente não realizar sua própria jurisdição.

Nesse sentido, como ensina Victor Rossetti (2018) ao citar o autor Francisco Rezek: “o exercício efetivo da jurisdição do tribunal [TIP] pressupõe o consentimento [...] do Estado do crime ou do Estado patrial do réu, senão de ambos."

Os debates acerca do tema são inúmeros e a tendência é, sim, uma maior amplitude do diálogo entre os atores da proteção multinível de Direitos Humanos, com o intento de intensificá-la e desenvolver-se um efetivo sistema multinível de proteção do qual o Brasil seja parte.

Nesse mesmo sentido, ao participar da conferência "Diálogos das Cortes Constitucionais e o Programa Harmonia com a Natureza", o ministro do Supremo Tribunal Federal, Edson Fachin (STF, 2019), declarou que “[...] é dever dos tribunais constitucionais construir um Direito Constitucional multinível, estabelecendo e desenvolvendo diálogo cooperativo entre conhecimento e experiência sobre o tema."

Isso porque, para o ministro (STF, 2019), “[...] a jurisdição constitucional tem papel essencial, nomeadamente por sua vocação contramajoritária, isto é, vocação para tutelar os direitos das minorias, para dar voz ao que não tem voz", para o que, o Direito "plural, multinível, cooperativo, dinâmico e participativo" é um instrumento de implantação (STF, 2019).

\subsubsection{A CONDENAÇÃO DO BRASIL NA CORTE INTERAMERICANA DE DIREITOS HUMANOS - O EXEMPLO DA FÁBRICA DE FOGOS NO RECÔNCAVO BAIANO}

A fim de ilustrar o que foi anteriormente exposto, faz-se mister trazer o exemplo do caso da Fábrica de Fogos no Recôncavo Baiano e a consequente condenação do Brasil pela Corte Interamericana por violação dos Direitos Humanos.

Trata-se de tragédia ocorrida em 1998, na cidade de Santo Antônio de Jesus/BA, quando 64 pessoas morreram, dentre as quais a grande maioria eram crianças e mulheres negras (CIDH, 2018). 
Ao analisar o caso, a Corte Interamericana (CIDH, 2018) entendeu que o Brasil, apesar de conhecedor das atividades perigosas, das flagrantes irregularidades e do perigo iminente à vida e saúde de todos os trabalhadores, optou por não inspecionar ou fiscalizar, cujo descaso do Poder Público se deu por “discriminação estrutural”.

Na sentença, a Corte Interamericana (2018) condenou o país a adotar inúmeras medidas de caráter estrutural que assegurem que tragédias deste tipo não se repitam, bem como, determinou que o país responsabilize criminalmente e civilmente os responsáveis pela explosão, além da adoção de medidas reparatórias às vítimas e familiares.

O que se observa, portanto, é que em que pese haja a condenação, não se vislumbra uma coercitividade ou efetividade das decisões internacionais, posto a lacuna jurídica que recai sobre a execução dessas condenações.

Tanto o é, que a Corte precisa determinar que o país por si só adote medidas hábeis a promover o resultado pretendido pela condenação. Todavia, inexiste qualquer sanção ou procedimento eficaz que possa ser adotado numa possível omissão do Brasil na execução dessa sentença.

Este é um dos 9 (nove) casos em que o Brasil foi condenado pela Corte Interamericana de Direitos Humanos e, com frequência, o que se vê é a esquiva das obrigações assumidas pelo pacto internacional, ao desconsiderar precedentes e determinações da Instituição Internacional, o que, por sua vez, distancia o país das diretrizes propostas pelas Organizações Externas e de uma tutela multinível de direitos humanos estruturada e eficiente.

\subsection{A TUTELA MULTiníVEL EM ÂMBito SUBNACIONAL E NACIONAL BRASILEIRA}

Finalmente, em que pese tenha se concluído que o Brasil não integra um sistema multinível efetivo e estruturado, apesar de possuir instrumentos nacionais e internacionais que protegem os Direitos Humanos, internamente é possível identificar a existência de um sistema multinível no âmbito nacional e subnacional formado pelas instituições, os Estados-federados e Estado-nação.

Assim como outrora explicado, no modelo Europeu, os direitos humanos são tutelados em pelo menos quatro níveis, dentre os quais, tem-se o subnacional, no qual as unidades podem vir a consagrar em suas ordens jurídicas certos direitos humanos e, nessa ocasião, é possível verificar direitos reconhecidos na esfera sub-estatal em relação hierárquica com a 
ordem constitucional nacional, de forma que a tutela multinível dos direitos humanos se confunde com o estudo do direito constitucional nacional do Estado.

Como se sabe, cada Estado-federado brasileiro possui sua própria constituição e leis, ao passo em que, o Estado-nação é regido pela Constituição Federal, à qual todos se submetem.

Bem assim, o sistema judiciário brasileiro se apresenta tanto em Tribunais Regionais, quanto em Tribunal Constitucional, além de adotar o duplo grau de jurisdição como princípio constitucional.

Destarte, muito embora a concepção do constitucionalismo multinível determine que a tutela dos direitos não se limite mais somente aos próprios Estados-nação, superando a noção de "soberania-território-povo", é possível falar em sistema multinível de direitos no âmbito subnacional como instrumento de promoção, efetivação e proteção dos Direitos Humanos.

\section{AS VANTAGENS E DESAFIOS DA TUTELA MULTINÍVEL DE DIREITOS HUMANOS}

Finalmente, por mais que este não seja o objeto da presente pesquisa, para corroborar com a formação de juízo de valor do leitor acerca da tutela multinível, faz-se mister um pequeno adendo acerca das suas vantagens e desafios.

Para Silva e Silva (2016, p. 52), a tutela multinível dos direitos humanos traz como vantagem uma proteção extra que pode suprir eventuais lacunas, permitir que outras instituições, além do Estado, também atuem como garantidoras dos direitos fundamentais, além de possibilitar maior acesso à justiça por parte dos cidadãos através de outros tribunais além dos nacionais.

Ao mesmo tempo, o "[...] contexto internacional torna-se uma ameaça credível para conseguir que autoridades nacionais relutantes protejam os direitos humanos [...]", o que se torna um notório incentivo à proteção dos direitos humanos, para se evitar litígio internacional (URUEÑA, 2014, p. 27).

Bem assim, em perspectiva nacional é possível observar essa influência dos instrumentos internacionais no posicionamento dos tribunais nacionais que passam a exercer jurisdição na proteção dos direitos humanos.

Apesar disso, a existência de níveis distintos de proteção dos direitos fundamentais, em que pese conduza à ideia de ser muito vantajosa, também reflete riscos, posto que se 
tratam de ordem jurídicas distintas que, inúmeras vezes, podem falar sobre coisas diferentes com as mesmas palavras (DA SILVA; SILVA, 2016, p. 45).

No caso europeu, por exemplo, Giovanni Damele e Francesco Pallante (2014) apresentam objeções ao de cunho prático e teórico à existência de um maior número de juízos nos termos intrínsecos da tutela multinível.

Para os autores, existem três aspectos críticos na proteção multinível: problemas decorrentes da exigência de coordenação das diferentes esferas de legalidade que sobrepõe, ou seja, a coordenação entre a legalidade legal, constitucional, comunitária, convencional e internacional; bem como, o fato de a mesma forma linguística que, nas disposições produzidas nos diferentes níveis do ordenamento, pode especificar um direito, não ter em todos os níveis o mesmo significado, tornando-se imprecisa a comparação das tutelas oferecidas em diferentes âmbitos para o mesmo direito; e, ainda, o fato de não ser absolutamente claro o significado de oferecer proteção em nível para direitos de um determinado ordenamento, considerando que "[...] toda decisão sobre direitos implica uma ponderação dos mesmos", enquanto que, "aumentar a tutela de um direito implica diminuir a de um outro [...]", assim, não teria sentido determinar qual o nível máximo da tutela de determinado direito (DAMELE; PALLANTE, 2014, p. 260).

Além desses que são de ordem prática, de um ponto de vista teórico, Damele e Pallante (p. 260) entendem que "[...] quem atribuiu a tutela dos direitos, em primeiro lugar, à fiscalização jurisdicional - nacional e supranacional em colaboração - inevitavelmente desvaloriza o momento da decisão democrática sobre os próprios direitos [...]”, de forma que se sobrepõe o jusnaturalismo à ideia de que as regras jurídicas implicam a positivação das decisões políticas.

É essa sobreposição que, nas lições dos autores, produz uma ruptura entre poder e direito que permite aos defensores da tutela multinível afirmar a existência de uma Constituição Europeia, apesar de a União Europeia não ter "[...] domínio das próprias regras fundamentais [...]" e ser "desprovida de uma comunidade política de referência[...]" (DAMELE; PALLANTE, 2014, p. 261).

Assim, a tutela multinível de direitos “[...] revela uma ulterior fraqueza, pois reenvia a própria tutela para sujeitos - os juízes europeus - muito mais livres, do ponto de vista da discricionariedade, do que os juízes nacionais [...]”, de forma que o resultado efetivo da tutela multinível (oriundo da jurisdição supranacional), “[...] depende mais da vontade dos juízes do que de vínculos decorrentes do texto.” (DAMELE; PALLANTE, 2014, p. 262). 
Por esse aspecto, então, a efetividade e qualidade da tutela "não dependeria da quantidade de sujeitos envolvidos, mas sim da atitude do sujeito ao qual o próprio sistema entrega a autoridade para pronunciar a última palavra." (DAMELE; PALLANTE, 2014, p. 268).

Nesse sentido, Urureña (2014, p. 26) destaca que a proteção multinível pode ser também elitista, implicar em uma redistribuição do poder institucional, dando mais poder aos tribunais que ao legislativo e executivo, de extrema burocratização à emancipação através dos direitos humanos e, por se focar essencialmente no discurso jurídico, a tutela multinível pode também “[...] limpar da política conflitos sociais que são, na realidade, políticos por antonomásia." (URUREÑA, 2014, p. 26).

Não apenas isso, arrisca-se, ainda, uma desmobilização da sociedade civil que, atrelada ao "[...] protagonismo exagerado da proteção internacional dos direitos humanos pode acabar deslocando outros mecanismos de mobilização que visam transformar a sociedade." (URUEÑA, 2014, p. 28).

Ou seja, esse protagonismo pode fazer com que a sociedade se diminua, na crença de que o responsável pela proteção e pelo clamor aos direitos humanos é o instrumento internacional, e não o próprio povo, quando, em verdade, a mobilização social "[...] pode ser muito mais eficaz e gerar mudanças mais profundas na sociedade[...]” (URUEÑA, 2014, p. 28).

\section{CONCLUSÃO}

A Tutela Multinível advém da proteção de Direitos, em níveis que não mais se limitam aos próprios Estados-nação, superando-se a noção de soberania através da participação de outros atores na tutela dos Direitos Humanos em níveis subnacionais, nacionais e supranacionais.

Em nível internacional, a Europa é considerada o berço do conceito de constitucionalismo multinível, através do qual as Ordens Constitucionais Internas de cada Estado-nação devem ser interligadas na proteção de Direitos da Pessoa Humana, que se conectam também à "Constituição" da União Europeia.

Ao passo em que, na Europa, existe um sistema multinível estruturado pela concepção de Direito Comunitário da União Europeia, não se vislumbra um sistema multinível estruturado e efetivo de proteção dos Direitos Humanos no âmbito interamericano. 
Neste cerne, em que pese existam instrumentos que reflitam, em limitada proporção, uma proteção multinível de direitos, organizados através da Organização dos Estados Americanos e inseridos na Constituição Nacional dos países latino-americanos, no Pacto de San José da Costa Rica, pelo Sistema Interamericano e também pelo Tribunal Penal Internacional e o Estatuto de Roma, dos quais o Brasil é signatário, conclui-se que não há, no âmbito brasileiro, uma efetiva tutela multinível que submeta os Direitos Humanos à jurisdição internacional.

Isso porque, este autor considera por proteção multinível a tutela de direitos em nível subnacional, nacional e internacional, através de organizações e mecanismos que promovam e efetivem os direitos tutelados em um sistema comunitário, cujo as decisões sejam hábeis a promover resultados independentemente de qualquer ato interno do Estado-nação e além de sua própria soberania, de forma que não careçam de uma confirmação ou execução por um órgão nacional.

Com efeito, não há uma jurisdição internacional à qual o Brasil tenha aderido que exerça sua jurisdição em nível de cooperação e não de subsidiariedade ou que se coloque em nível superior ao constitucionalismo nacional, com força para executar suas decisões, como se pôde observar pelo exemplo trazido ao trabalho da tragédia da fábrica de fogos no Recôncavo Baiano, onde o Brasil foi condenado a cumprir diversas determinações, porém, não se vislumbra efetividade ou coercitividade da decisão.

Muito ao contrário, há na própria condenação uma determinação para que, internamente, o país adote medidas de responsabilização dos culpados e reparo das vítimas.

Tanto é, que os tratados internacionais de direitos humanos internalizados pelo Brasil em nível de emenda constitucional podem ser objetos de controle de constitucionalidade e pode ser declarado inconstitucional, o que poderia ter acontecido com a Corte Interamericana de Direitos Humanos na recente divergência sobre a adequação da lei brasileira de anistia à Constituição Brasileira e à Convenção Americana.

Assim, quando se pergunta se existe, no âmbito brasileiro, um sistema multinível estruturado de proteção dos Direitos Humanos, a presente pesquisa responde que não.

Pode-se falar, porém, em tutela multinível em âmbito subnacional, considerando a organização interna dos Estados-federados, mas que não se confunde com o constitucionalismo multinível efetivo e tampouco com proteção multinível regional ou global, posto que não extrapola a ordem jurídica nacional. 


\section{REFERÊNCIAS}

ANDRADE, Régis Willyan da Silva. O diálogo entre os Direitos Fundamentais e os Direitos Humanos para criação de um Sistema Jurídico Multinível. Revista de Estudos Constitucionais, Hermenêutica e Teoria do Direito (RECHTD) 9(I):75-89, janeiro-abril 2017.

BRASIL. Constituição da República Federativa do Brasil. Disponível em: <

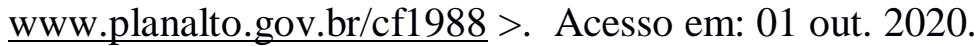

BRASIL. Decreto n. 4388, de 25 de setembro de 2002. Disponível em: < http://www.planalto.gov.br/ccivil_03/decreto/2002/d4388.htm.> Acesso em 08 out. 2020.

CIDH, Informe $\mathbf{N}^{\mathbf{0}}$. 25/18, Caso 12.428. Admissibilidade e Mérito. Empregados da Fábrica de Fogos de Santo Antônio de Jesus e seus familiares. Brasil. 2 de março de 2018. Disponível em: < https://www.oas.org/es/cidh/decisiones/corte/2018/12428FondoPt.pdf >. Acesso em 04 de outubro de 2020.

COIMBRA, Maria de Nazaré Costa Trigo. O círculo da escrita. O texto argumentativo e a consciência (meta) linguística no ensino secundário. 2012. 289 f. Tese (Doutorado em Educação) - Instituto da Educação. Universidade Lusófona de Humanidades e Tecnologias. Lisboa. 2012, p. 59.

CUNHA, Clarissa de O. G. M. da. Tutela multinível de direitos: Alternativa para a efetivação do pluralismo jurídico no novo constitucionalismo latino-americano. Revista Jurídica Unicuritiba. Curitiba. V. 03, n. 60, p. 498-529, Jul-Set. 2020.

DAMELE, Giovanni e PALLANTE, Francesco. A tutela multinível dos direitos: Quantidade é sinônimo de qualidade? 2014. p. 247-273. Disponível em: < https://iris.unito.it/handle/2318/154683. > Acesso em 02 out. 2020. ISBN: 9789899707337.

DESCARTES, René. Discurso do Método. 3. ed., ver. e ampl. São Paulo: Martins Fontes, 2007, P.33-34.

GALINDO, George Rodrigo B., URUEÑA, René e PÉREZ, Aida Torres. Proteção Multinível dos Direitos Humanos. Manual. 2014 - dhes.

KUHN, Thomas. A estrutura das revoluções científicas. 5 ed. São Paulo: Perspectiva, 1988, p. $46-48$.

LIMA, Flávia Danielle S. e VIEIRA, Drailton Ferreira. A tutela multinível de Direitos Fundamentais numa perspectiva dialógica: a proteção regional e nacional da presunção de inocência. Revista Juris Poiesis - Rio de Janeiro. Vol. 21 - n. 27, 2018, pg. 53-69, 2018.

PADILLA, Carmen Montesinos. Tutela multinivel de los derechos: Obstáculos procesales. Departamento Derecho Público Del Estado. Gatafe, enero, 2015. 
ROSSETTI, Victor. Tribunal Penal Internacional: o que é e como atua? 2018. Disponível em: $<$ https://www.politize.com.br/tribunal-penal-internacional/publicado $>$ Acesso em 08 out. 2020 .

DA SILVA, Alice Rocha e SILVA, Matheus Passos. A Ineficácia da Tutela Multinível dos Direitos Sociais na União Europeia. R. Opin. Jur., Fortaleza, ano 14, n. 18, p. 44-73, jan./jun. 2016.

STF, Notícias. STF sedia evento para promover diálogo entre as cortes constitucionais sobre a harmonia do homem com a natureza. 22 de abril de 2019. Disponível em: < http://www.stf.jus.br/portal/cms/verNoticiaDetalhe.asp?idConteudo=409112. >. Acesso em 20 de outubro de 2020.

OEA. Convenção Americana de Direitos Humanos ("Pacto de San José de Costa Rica"), 1969. Disponível em:

http://www.pge.sp.gov.br/centrodeestudos/bibliotecavirtual/instrumentos/sanjose.htm $>$. Acesso em: 02 de outubro de 2020.

ONU. Carta das Nações Unidas. 1945. Disponível em: < https://brasil.un.org/pt-br/91220carta-das-nacoes-unidas >. Acesso em: 02 de outubro de 2020.

POPPER, Karl. Lógica das Ciências Sociais. 3. ed. Rio de Janeiro: Tempo Brasileiro, 2004, p.14-15, 28-29. 